\title{
Analysis and Research on the Interactive Behavior of Teaching in the Digital Environment of University
}

\author{
Lijun Yang ${ }^{1, a}$ \\ ${ }^{1}$ Network Information Center, Tonghua Normal University, TongHua, Jilin, China \\ a634337308@qq.com
}

Keywords: Teaching interaction; Digital environment; Multi-media.

\begin{abstract}
No matter it is in the traditional concepts of education or the modern teaching model system, we advocate to have more interaction between the link to improve the students' attention, stimulate students interest in learning, and now under the environment of digital interactive teaching form more multiple and diverse, digital multimedia is widely used in teaching practice now, so if there is effective use digital multimedia and traditional teaching mode combined, so as to improve the quality of classroom teaching is our main research direction. This paper makes a detailed analysis of the problems existing in the multi media teaching interaction and solving methods, have a certain understanding and guidance on the teaching interactive behavior.
\end{abstract}

\section{Introduction}

With the continuous progress of modern science and technology, the continuous improvement of the level of teaching, digital multimedia technology has been more and more applied in classroom teaching, and has gradually become a mainstream teaching mode. At the same time, the multimedia teaching mode itself is in constant progress of evolution, function more powerful in the teaching position is gradually becoming prominent. The multimedia teaching model can be said to be a capable of interaction between students and teachers to put into the classroom teaching mode, can effectively improve the students' enthusiasm and activity. Since 90s, the computer technology has been gradually known to the public, using computer experimental teaching with multimedia technology also began teaching in computer. In the school of technology popularization. The Ministry of Education issued "on the strengthening of the undergraduate teaching work to improve the teaching quality of some Views $>$, and clearly pointed out that require schools to strengthen the campus network, construction of electronic library, digital multimedia teaching environment, which also multimedia teaching provides a favorable development space. But because of the multi-media teaching and there is no unified management and training, in the use of teaching in various regions occur naturally in a jagged, which also makes the multimedia teaching in Colleges and universities teacher-student interaction appeared by most educators pay close attention to the problem.

\section{The problems and deficiencies in classroom teaching interaction}

Excessive pursuit of courseware effect, ignoring the teaching process. The multimedia teaching stage, many teachers will use the transfer form of the courseware will be taught to the students, but in the process of making courseware, some teachers pursue courseware page layout is exquisite, diversity and animation design, while ignoring the courseware itself should play a role, sometimes so much decoration would be counterproductive, distracted the attention of students, so to reach the expected effect. In addition, classroom courseware generally by teachers' personal, too pursuit of courseware fancy, namely the cost of energy, often can not be refined to the final of the curriculum courseware into a blackboard instead of simply on the teaching content and copy, can not really cause students' interest and sympathy, so the lack of students' imagination, creativity and thinking ability, unable to play a supporting fundamental course for Use.

Lack of interaction between teachers and students. This is an important issue has been for many years in teaching, how to achieve the effective interaction between teachers and students, in 
theory, teaching itself should be a dynamic process between teachers and students, in addition to the course of knowledge exchange, there should also be thinking and emotional communication, active classroom atmosphere to help students learn the knowledge of the effective memory, at the same time, students' performance has a direct impact on the enthusiasm of teachers. So the teaching is the best effective communication between teachers and students and stimulate each other. But now most of the teaching mode is guided by teachers, for students every step of the study, this it is not the exchange and become indoctrinated. Using multimedia teaching and also should let the students take the initiative to find the problem, propose and analyze and solve the problems, rather than mechanical indoctrination, which makes the course boring.

Interactive form simplification. Nowadays multimedia advantage did not fully play out, teachers in the teaching process for multimedia applications also only stay in the simple display and Q \& a level, so that a single teaching mode and traditional teaching did not essentially different, can not give full play to the advantages of multimedia teaching. Teacher's understanding of multimedia education at present still need to be improved, from the simple teaching level gradually shifted to help students learn the level, which requires teachers strengthen the multimedia knowledge learning and mastering, effective use of multimedia resources for teaching practice, explore the diversification of multimedia teaching mode, flexibility, with an increase in the interaction between the students.

\section{Strategies and suggestions on the interaction between teachers and students in the classroom teaching under the digital environment}

Strengthening the teaching management in the digital environment. From the perspective of management of should pay more attention to the digital multimedia technology in the teaching application, to strengthen the teachers use technology training and ability improvement, for the development of multimedia application in teaching counseling, digital multimedia teaching provides a favorable environment for development and space, teachers are encouraged to use multimedia in teaching practice. Notice of deepening reform the teaching form, and actively adapt to the reform of teaching in the form of, in the system to ensure the teacher's work and rest time, reasonable arrangement of teacher of multimedia knowledge learning and teaching content design time and strengthen the hardware investment, actively promote and guarantee the teaching activities are carried out smoothly.

Teachers should change their ideas radically, and update the teaching methods in a timely manner. To change the mode of teachers should actively from the traditional teaching idea and the way to jump off, and actively adapt to the new environment changes and rapid adaptation from the original to teacher centered classroom teacher-student interaction teaching mode. To learn how to use a variety of teaching methods to stimulate students' autonomous learning ability and enthusiasm, the development of thinking ability, teachers from the original instilled into helper, from the ideological transformation, and then from the teaching mode thoroughly change. According to the different teaching students in accordance with their aptitude, set a variety of teaching methods and means, promoting the cultivation of students' practical ability and independent thinking ability, let the students really understand in the teaching of the knowledge significance.

Making courseware according to course content. The multimedia courseware is very popular in modern classroom teaching, but some courseware in classroom application does not fully show the real advantages of digital multimedia, in making courseware should also pay attention to fit with the curriculum content, teaching need to meet fully appropriate, in color, font settings and other aspects should pay attention to the collocation, do not take in addition, pay attention to set up courseware focused, simple and logical, in setting questions should pay attention to whether the typical problems, whether it is beneficial to guide students to think, there is a sound step, pay attention to sound effects such as video insertion, the length of time a little more. The most important thing is to pay attention to interaction. Appropriate increase to interact with the students.

Strengthen the students' understanding of digital information technology and cultivate students' learning interest. Digital multimedia technology reference, is, in the final analysis, in order to improve the students' interest in learning, promote teaching activities smoothly and improve 
the teaching quality of continuous progress. Therefore students in digital multimedia applications play a crucial role. Therefore, in order to according to the students' characteristics, not only will digital multimedia means as a way to reduce the workload, and should be through the use of voice, image, animation and so on, combined with the advantages of the traditional mode of education, stimulate the students' vision, hearing, different sensory experience, fully mobilize the enthusiasm of students, so hand, eye, brain cooperate with each other, enhance their subjective initiative in learning.

\section{Conclusion}

Influence of teacher's vision is very important for students in learning and life, so it is in which aspects of teaching, teachers should focus on is to cultivate their professional qualities, enhance self-cultivation, pay attention to participate in the study and training, to strengthen the understanding and learning of digital media and improve the quality of class. Always, all the educators continue to practice and hope to achieve goals, strengthen the interaction between teachers and students in the multimedia classroom, is very beneficial to improve the quality of class. And for the production of classroom courseware, to cultivate students' interest in multimedia classroom. For the development of modern digital multimedia technology, whether it is school or a teacher, and students have great significance should not be underestimated. Increase the multimedia teaching technology is put into force, strengthen the study of the interaction between teachers and students teaching, Are conducive to the improvement of teaching quality, also will create good educational technology learning atmosphere. You can also predicted that the interactive teaching in the future under the digital environment will become the mainstream teaching mode, and in China's colleges and universities will also on this road, greater achievements.

\section{References}

[1] Wang Wei; Gu Xiaoqing. A new exploration of classroom analysis techniques for the support of teachers' professional development [J]. China Educational Technology. 2004. 07.

[2] Tian Jianlin,Hu Weixing. Construction and application mode of intelligent classroom system [J]. China Educational Technology. 2011. 09.

[3] Avril M.Loveless, Li Yang, Ji zhe, Yang Yuqin. Literature Review in Creativity, New Technologies and Learning [J]. Journal of Distance Education. 2009.04.

[4] Zhong Zhiqiang. Analysis and Evaluation on Interaction Education [J]. Journal of Anshan Normal University.2010.4.

[5] Zhang Ludan, Wang Ying, pan Yuxia. Study on the characteristics of teachers' classroom teaching cases of information technology experts -- Based on interaction analysis system [J]. E-Education Research.2011.07.

[6] Sun Zhong. tResearch on basic skills of pre service teachers' information classroom teaching [J]. E-Education Research.2011.07.

[7] Jin Jianfeng. Research on the integration of classroom teaching technology under the environment of information technology [D].East China Normal University.2010.

[8] Li Qiying. A case study of interaction between teachers and students in the information environment [D]. Central China Normal University.2011. 